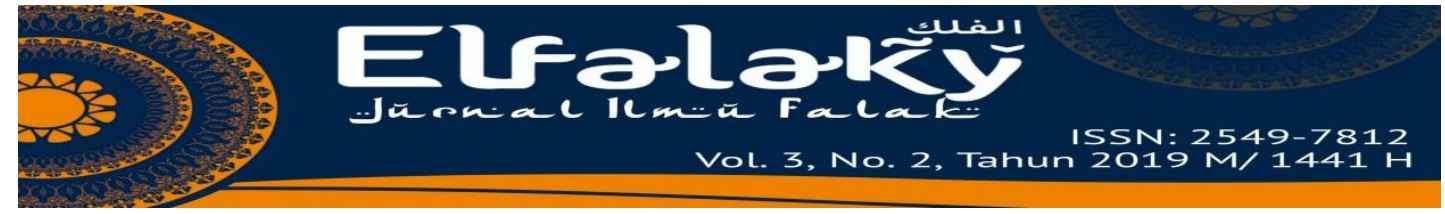

\title{
Eksplorasi Pemikiran Abu Ma'shar Al Falaky Tentang Manuasia dan Bintang
}

\author{
Mursyid Fikri \\ Universitas Muhammadiyah Makassar (UNISMUH) \\ mursyidfikri@gmail.com
}

Muh. Rasywan Syarif

Fakultas Syariah dan Hukum UIN Alauddin Makassar

rasywan.syarif@uin-alauddin.ac.id

\begin{abstract}
Of the many sciences that once recognized his belief in giving color to the life of Islam, one of them is the science of astrology. One of the great scholars who introduced the widespread science of astrology was abu ma'shar Al-falaky, the title of al-falaky given to him because of his greatness in connecting natural events with human life. Therefore this paper will discuss some of the thought of abu ma'shar al-falaky in ash book ma'shar Alfalaky which discussed 14 chapters then the author tries to peel 4 chapters between the chapters namely lesson losing chapter, chapter year, ill-fitting article and article human relationship with the star. By combining with scientific studies.
\end{abstract}

Key Words : Abu Ma'Shar,thought, Astrology,

\section{A. PENDAHULUAN}

Astrologi tidak sepenuhnya sama dengan astronomi. Astronomi sering dikelirukan dengan astrologi, dan sebaliknya. Karena banyak ilmuwan menganggap bahwa astrologi tidak mengikuti metode ilmiah dari negara barat, maka kebanyakan mereka secara umum menolak astrologi untuk menjadi ilmu astronomi dan cukup mengklasifikasikan sebagai ilmu semu ${ }^{1}$. Astrologi secara mendalam pernah digabungkan dengan astronomi, dan perbedaan jelas di antara keduanya diungkap kembali pada masa Galileo. Dia ialah orang pertama yang menggunakan metode ilmiah untuk menguji pernyataan obyektif tentang langit.

${ }^{1}$ Ophelia, Sukses Finansial lewat astrologi dan peta kehidupan, (Jakarta: Penerbit Buku Kompas, 2010) h.15 
Astrologi berasal dari kata Yunani yang berarti ilmu tentang bintangbintang. Ilmu ini awalnya digunakan oleh bangsa Kaldea yang hidup di Babilonia pada permulaan tahun 3000 SM (Sebelum Masehi). Jika kita mendasari pada peninggalan artefak-artefak kuno, astrologi telah dikenal lebih tua lagi yaitu sekitar tahun 15.000 SM. Artefak-artefak ini banyak ditemukan di daerah Timur Tengah $^{2}$. Bangsa Cina di Asia kemudian mengadopsi ilmu ini untuk digunakan dalam kesehariannya. Astrologi mendasari ilmunya pada pergerakan benda-benda langit antara lain matahari, planet-planet, bintang, dan bulan. Para astrolog percaya bahwa posisi benda-benda langit ini berpengaruh pada kehidupan manusia dan peristiwa masa depan yang akan terjadi dapat diramalkan berdasarkan posisi benda langit tersebut. Bagaimana dengan astronomi?

Astronomi merupakan ilmu peramalan juga namun yang diramal berbeda dengan peramalan astrologi. Penemuan empat satelit Jupiter oleh Galileo Galilei dengan menggunakan teropongnya membawa umat manusia kepada pemahaman baru terhadap objek langit. Pemanfaatan hukum fisika untuk menjelaskan pergerakan benda langit pada era Issac Newton dengan Hukum Gravitasi Newtonnya semakin menegaskan perbedaan antara astronomi dengan astrologi. Astronomi tidak menghubungkan pergerakan benda-benda langit terhadap kehidupan manusia. Astronomi merupakan ilmu sains yang mempelajari, memahami, dan meramalkan peristiwa alam yang terjadi di alam semesta. Tapi kadang kita sulit untuk membedakan antara astronomi dan astrologi.

\title{
B. BIOGRAFI KEILMUAN ABU MAS'HAR ALFALAKY
}

\begin{abstract}
Abu Masyar Ja'far Ibnu Muhammad Ibnu Umar juga dikenal sebagai al-Falaki atau Ibn Balkhi, Latin sebagai Albumasar, Albusar, atau Albuxar adalah astronom dan filsuf Islam asal Persia. Ia dianggap sebagai Astronom terbesar dari Abbasiyah di Baghdad. Ia menulis sejumlah buku pedoman praktis tentang astrologi, Karya-karyanya ditulis dalam bahasa Arab dan Persia.
\end{abstract}

${ }^{2}$ Ivan Taniputra, Astrologi Dan sejarah Dunia, (Yogyakarta: Aplus Book, 2009) h. 17-18 
Abu Ma'shar al-Balkhi lahir 10 Agustus 787 (abad IX) di Balkh, Khurasan Balkh, sebuah kota di sebelah timur Khurasan. Abu Ma'shar ahli astronomi dan astrologi. Astrologi yang dimaksudkan di sini adalah yang berhubungan dengan rasi bintang, bukan ilmu nujum. Setelah menyelesaikan studi Tradisi Islam Klasik di Baghdad, Abu Ma'shar mencurahkan seluruh perhatiannya untuk memelajari astronomi dan astrologi.

Sejak remaja, Abu Ma'shar sudah memelajari tradisi kuno Arab. Ia terus memperdalam pengetahuannya di bidang itu sambil memelajari bidang lain, seperti astronomi. Pada masa itu, ilmu astrologi belum dihubungkan dengan ilmu nujum. Abu Ma'shar menguasai astrologi yang bermuatan sains. Ia menghasilkan sejumlah karya astrologi yang banyak dipengaruhi prinsip dasar dan hukumhukum astronomi. Karyanya itu berisi sejumlah pengamatan yang telah dilakukannya, salah satunya adalah mengamati komet. Sehubungan dengan hal itu, Tycho Brahe berpendapat bahwa Abu Ma'shar adalah ilmuwan pertama yang menyanggah pendapat Aristoteles bahwa dia telah mengamati komet-komet di sfera Planet Venus. Tycho Brahe menulis pendapat tersebut dalam bukunya yang berjudul Progymnastica.

Abu Ma'shar juga pernah menghasilkan sebuah himpunan Tabel Astronomi (Zij) dan sebuah risalah yang terdiri dari delapan buku. Risalah yang berjudul al-Madkhali al-Kabir il Ilm al-Nujum (Pengantar Besar ke Ilmu Astrologi) ini telah dua kali diterjemahkan dalam bahasa Latin. Pertama, oleh Johanes Hispalensis pada tahun 1130. Kedua, oleh Hermanus Secundus pada tahun 1150 .

Keberadaan karya-karya Abu Ma'shar sangat memengaruhi para ilmuwan Timur dan Barat. Pada abad pertengahan, para ilmuwan Eropa memelajari Hukum Pasang Surut Air Laut dari buku Abu Ma'shar. Dalam penjelasan itu terdapat beberapa uraian yang sangat mengagumkan karena sesuai dengan hasil pengamatan yang dilakukan oleh sejumlah ilmuwan modern. Misalnya, teori tentang pengaruh bulan terhadap angin dan curah hujan. Hingga kini, karya tersebut masih sering dijadikan bahan rujukan oleh para ahli matematika dan 
geografi. Selain menguasai ilmu perbintangan, Abu Ma'shar al-Balkhi dikenal pula sebagai seorang filosof.

Keiji Yamamoto dalam tulisannya tentang sejarah hidup Abu Mashar mengungkapkan, ilmuwan Muslim terkemuka di abad ke-9 M itu terlahir pada 10 Agustus 787 M di Balkh, Persia (sekarang Afganistan). Sejatinya ia memiliki nama lengkap Jafar ibnu Muhammad Abu Mashar al-Balkhi.

Selain dikenal dengan sebutan Abu Mashar, atrolog yang satu ini juga biasa disebut dengan panggilan Abulmazar. Abu Mashar merupakan seorang ilmuwan serbabisa. Selain dikenal sebagai seorang ahli astrologi (ilmu perbintangan), Abu Mashar juga menguasai matematika, astronomi, dan filsafat Islam. Ia menekuni matematika saat berusia 47 tahun, setelah kenal dan berkecimpung dalam dunia astrologi. ${ }^{3}$

Ia merupakan murid dari seorang guru yang sangat legendaris, yakni alKindi, ilmuwan Muslim di abad ke-8 M. Seperti sang guru, nama Abu Mas'har begitu populer di dunia Barat. Abu Ma'shar telah berjasa menyatukan pelajaran ilmu perbintangan dari berbagai sumber Islam yang luas.

Abu Masyar Ja'far Ibnu Muhammad Ibnu Umar wafat pada pada 9 Maret 886 Wasit, Irak.

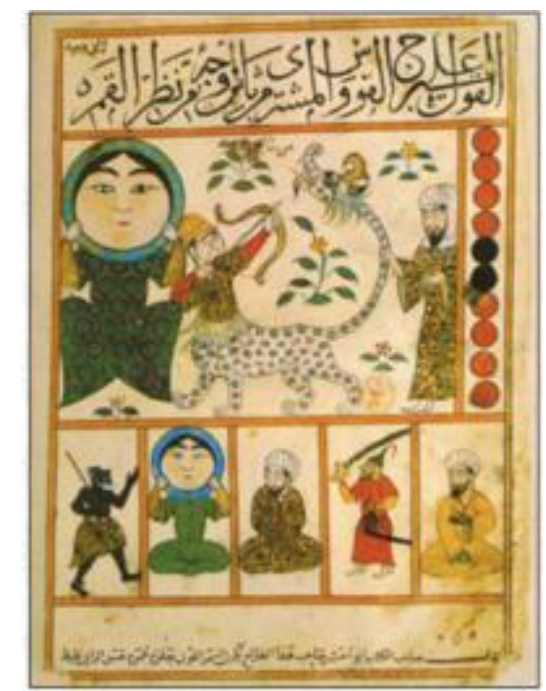

Contoh naskah Abu Ma'shar

${ }^{3}$ http://www.sarkub.com/abu-mashar-astrolog-muslim-dari-persia/ 


\author{
ELFALAKY: Jurnal Ilmu Falak \\ Vol. 3. Nomor 2. Tahun $2019 \mathrm{M} / 1441 \mathrm{H}$ \\ pada astrologi, $850 \mathrm{AD}$
}

\title{
Pengenalan untuk astrologi
}

- $\quad$ Kitab al-mudkhal al-Kabir pengenalan astrologi yang menerima banyak terjemahan ke bahasa Latin dan Yunani mulai dari abad ke-11. Ini memiliki pengaruh yang signifikan terhadap filsuf Barat, seperti Albertus Agung.

- Kitab Mukhtasar al-mudkhal, sebuah versi singkat di atas, kemudian diterjemahkan ke bahasa Latin oleh Adelard of Bath.

\section{Astrologi sejarah}

- $\quad$ Kitab al-Milal wa-l-' Duwal ("Buku tentang agama dan dinasti")

- $\quad$ Fi dzikir ma tadullu ' alayhi al-ashkhāṣ al-' ulwiyya ("Pada indikasi adanya benda-benda langit"),

- Kitab al- ' dalālāt ala al-ittișālāt wa-al-qirānāt kawākib ("Kitab indikasi adanya konjungsi planet"),

- $\quad$ Kitab al-ulūf ("Kitab ribu"), diawetkan hanya dalam ringkasan oleh Sijzī.

- Kitāb taḥāwīl Sini al-'alam (Bunga-bunga Abu Ma'shar), menggunakan horoskop untuk memeriksa bulan dan hari dalam setahun. Itu adalah petunjuk bagi astrolog. Hal itu diterjemahkan di abad ke-12 oleh John of Seville.

\section{Genethlialogy}

- Kitāb tahāāwil Sini al-mawālīd ("Kitab revolusi dari tahun nativities"). diterjemahkan ke dalam bahasa Yunani pada 1000, dan dari bahwa terjemahan ke dalam bahasa Latin pada abad ke-13.

- Kitāb al-Rijal mawālīd wa-' 1-Nisa ' ("Kitab nativities pria dan wanita"), yang beredar luas di dunia Islam.

\section{Buku yang tersedia dalam bahasa Latin dan terjemahan Yunani}

- De Magnis coniunctionibus, ed.-transl. K. Yamamoto, Ch. Burnett, Leiden, 2000, 2 jilid. (Arabic \& teks Latin)

- $\quad$ De revolutionibus nativitatum, ed. D. Pingree, Leipzig, 1968 (teks Yunani) 
- Liber florum Diterjemahkan oleh James Herschel Holden di Lima Astrolog Medieval (Tempe, Az:. AFA, Inc, 2008): 13-66.

- Introductorium Maius, ed. R. Lemay, Napoli, 1995-1996, 9 jilid. (Arabic text \& dua terjemahan Latin)

- Ysagoga minor, ed.-transl. Ch. Burnett, K. Yamamoto, M. Yano, LeidenNew York, 1994 (Arab \& Latin text

\section{KAJIAN PEMIKIRAN ABU MAS'HAR AL FALAKY}

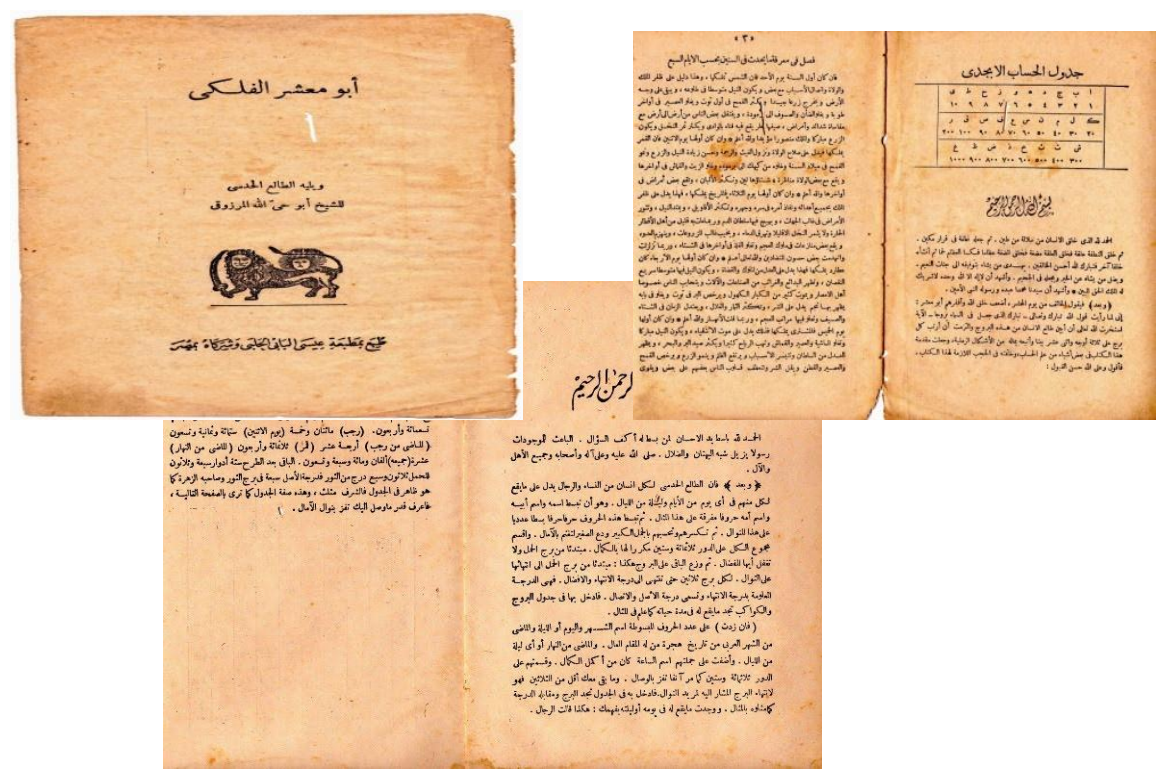

\section{PENGERTIAN ASTROLOGI}

Astrologi tidak sepenuhnya sama dengan astronomi. Astronomi sering dikelirukan dengan astrologi, dan sebaliknya. Karena banyak ilmuwan menganggap bahwa astrologi tidak mengikuti metode ilmiah dari negara barat, maka kebanyakan mereka secara umum menolak astrologi untuk menjadi ilmu astronomi dan cukup mengklasifikasikan sebagai ilmu semu. ${ }^{4}$ Astrologi secara mendalam pernah digabungkan dengan astronomi, dan perbedaan jelas di antara 2009) h. 45

${ }^{4}$ Hudoyo ki hadayadiputro, Dasar-dasar Astrologi Hindu, (Surabaya: Penerbit Paramita, 
keduanya diungkap kembali pada masa Galileo. Dia ialah orang pertama yang menggunakan metode ilmiah untuk menguji pernyataan obyektif tentang langit.

Astrologi berasal dari kata Yunani yang berarti ilmu tentang bintang-bintang. Ilmu ini awalnya digunakan oleh bangsa Kaldea yang hidup di Babilonia pada permulaan tahun 3000 SM (Sebelum Masehi). Jika kita mendasari pada peninggalan artefak-artefak kuno, astrologi telah dikenal lebih tua lagi yaitu sekitar tahun 15.000 SM. Artefak-artefak ini banyak ditemukan di daerah Timur Tengah. Bangsa Cina di Asia kemudian mengadopsi ilmu ini untuk digunakan dalam kesehariannya. Astrologi mendasari ilmunya pada pergerakan benda-benda langit antara lain matahari, planet-planet, bintang, dan bulan. Para astrolog percaya bahwa posisi benda-benda langit ini berpengaruh pada kehidupan manusia dan peristiwa masa depan yang akan terjadi dapat diramalkan berdasarkan posisi benda langit tersebut. Bagaimana dengan astronomi?

Menurut kamus Merriam-Webster, Astrologi (Astrology): "The divination of the supposed influences of the stars and planets on human affairs and terrestrial events by their positions and aspects." Dari definisi tersebut jelas bahwa para pakar astrologi percaya bahwa posisi benda-benda langit (planet dan bintang) berpengaruh pada kehidupan manusia dan peristiwa masa depan yang akan terjadi dapat diramalkan berdasarkan posisi benda langit tersebut. ${ }^{5}$

Astrologi merupakan ramalan yang dibangun melalui interpretasi pengaruh bintang-bintang dan planet-planet terhadap urusan-urusan di bumi dan nasib atau takdir manusia. Pada zaman kuno astrologi tidak dapat dipisahkan dengan astronomi. Astrologi mulai dikenal di Mesopotamia (millennium ketiga SM) dan menyebar ke India, tetapi kemudian berkembang di peradaban Yunani. Astrologi memasuki kebudayaan Islam sebagai bagian dari tradisi Yunani dan dikembalikan ke budaya Eropa pada zaman pertengahan. Menurut tradisi Yunani, surga dibagi berdasarkan menurut 12 rasi bintang zodiak, dan cahaya dan posisi bintang yang pada berbagai interval tersebut mempengaruhi kejadian dan urusan manusia.

\footnotetext{
${ }^{5}$ Ensiklopedia Britannica, dictionary Merriam Webster online, diakses pada 29 September 2017 M.
} 
Astrologi juga merupakan bagian penting dalam peradaban Cina kuno. Horoskop pada setiap bayi yang lahir menentukan seluruh titik waktu kehidupan mereka (junctures of life). Pada pada zaman modern sekarang, astrologi masih dipercaya secara luas untuk mempengaruhi kepribadian.

2. Pemikirannya Tentang astrologi

Dalam kitab Abu Ma'syar Al-Falaki atau dalam edisi terjemah Jawanya berjudul Abu Ma'syar Al-Falaki; Ilmu Palintangan Ngaweruhi Kahanane Manusia disebutkan bahwa metode yang digunakan berbeda dengan metode pitungan Jawi. Jika pitungan Jawi menggunakan rumus, di antaranya, pancawara dan saptawara, maka $A b u$ Ma'syar menggunakan rumus hisab Abajadun. ${ }^{6}$

\begin{tabular}{|c|c|c|c|c|c|c|c|c|c|}
\hline ज & b & $\tau$ & j & و & D & د & ج & ب ب & 1 \\
\hline 10 & 9 & 8 & 7 & 6 & 5 & 4 & 3 & 2 & 1 \\
\hline J & ق & ص & ق & $\varepsilon$ & س & ن & p & $J$ & s \\
\hline 200 & 100 & 90 & 80 & 70 & 60 & 50 & 40 & 30 & 20 \\
\hline & $\dot{\varepsilon}$ & b & ض & j & $\dot{\tau}$ & $\dot{H}$ & ت & ش ش & \\
\hline & 1000 & 900 & 800 & 700 & 600 & 500 & 400 & 300 & \\
\hline
\end{tabular}

Pada bagian pengantar ditulis:

${ }^{6}$ Anwar Kasir, Kitab Primbon Terjemah Abu Ma'syar Al-Falaki, (Surabaya: Maktab Said bin Nashir bin Nabhan, 1902), 2-3 
"Sesungguhnya ketika aku berpikir firman Allah: Maha suci Allah yang menjadikan di langit gugusan-gugusan bintang dan Dia menjadikan juga padanya matahari dan bulan yang bercahaya (QS. Al-Furqon: 61). Aku istikharah pada Allah Swt agar bisa menerangkan tentang manusia dari aspek perbintangan, dan aku haturkan agar tertib di setiap bintang yang dibagi tiga jenis jalan dan 12 tempat karena menggunakan cara-cara meramal"?

Keterangan di atas menunjukan bahwa latar belakang penulis kitab tersebut mendalami ilmu hisab/ falak/ astrologi adalah berangkat dari keingintahuannya akan rahasia di balik firman Allah dalam surat Al-Furqon ayat 61, dan kemudian ia melakukan istikharah.

Abu Ma'syar Al-Falaki memuat 14 pasal dan pembahasan, yaitu: (1)

Pasal tahun, (2) Pasal pengingat yang akan terjadi dalam satu tahun, (3) Pasal hari, (4) Pasal waktu siang, (5) Pasal waktu malam, (6) Perhitungan menang kalah, (7) Pasal perhitungan bergaul, berteman, jodoh, dan persaudaraan, (8) Pasal perhitungan sakit, (9) Pasal perhitungan orang hamil, (10) Pasal perhitungan orang bepergian, (11) Pasal perhitungan orang melahirkan, (12) Jalan berguna, (13) Pasal perbintangan manusia dan gugusan bintang, (14) Pasal pengingat gugusan bintang dan perbintangan

Pasal pertama tentang tahun misalnya, disebutkan bahwa tiap-tiap hari, mulai Ahad sampai Sabtu memiliki pengaruh terhadap jalannya kehidupan selama satu tahun, tergantung hari apa yang mengawali tahun tersebut. Kita ambil satu contoh, tahun 2014 yang diawali dengan hari Rabu. Hari Rabu dikuasai oleh 'Athorod (Merkurius), menunjukan keadilan raja dan para hakim, air bengawan cukup namun pada akhirnya akan surut, banyak kerajinan dari batu yang berbentuk aneh, orang banyak membuat perkumpulan, banyak orang besar (pemimpin) yang mati, tahun tersebut harga kacang murah mulai bulan Oktober dan akan naik pada November. Di langit terlihat bintang baru yang menandakan naiknya harga buah-buahan hingga datang musim penghujan, orang asing merajalela. ${ }^{8}$ 
Ramalan tersebut dibuat berdasarkan peredaran benda-benda langit yang menguasai masing-masing hari. Hari Ahad dikuasai oleh Syams (Matahari), hari Senin dikuasai oleh Qomar (Bulan), hari Selasa dikuasai oleh Marikh (Mars), hari Rabu dikuasai oleh 'Athorod (Merkurius), hari Kamis dikuasai oleh Musytaro (Jupiter), hari Jum'at dikuasai oleh Zahroh (Venus), hari Sabtu dikuasai oleh Zahl (Saturnus).

Contoh lain, dalam pasal enam yang membahas tentang keberuntungan dan naas pada tiap jamnya, disebutkan bahwa ternyata tiap jam dalam satu hari memiliki peruntungannya masing-masing yang bergantung pada bintang yang menguasai waktu tersebut. ${ }^{9}$

1. Malam Ahad

$\begin{array}{lll}18.00-19.00 & \text { Merkurius } & \text { Tidak karuan } \\ 19.00-20.00 & \text { Rembulan } & \text { Beruntung } \\ 20.00-21.00 & \text { Saturnus } & \text { Naas } \\ 21.00-22.00 & \text { Jupiter } & \text { Beruntung } \\ 22.00-23.00 & \text { Mars } & \text { Naas } \\ 23.00-24.00 & \text { Matahari } & \text { Beruntung } \\ 24.00-01.00 & \text { Venus } & \text { Beruntung } \\ 01.00-02.00 & \text { Merkurius } & \text { Tidak karuan } \\ 02.00-03.00 & \text { Rembulan } & \text { Beruntung } \\ 03.00-04.00 & \text { Saturnus } & \text { Naas } \\ 04.00-05.00 & \text { Jupiter } & \text { Beruntung } \\ 05.00-06.00 & \text { Mars } & \text { Naas } \\ \text { dan seterusnya. } & & \end{array}$

Sedangkan pasal terakhir menjelaskan perhitungan manusia dan bintangnya dengan gugusan bintangnya (buruj) untuk mengetahui hal ikhwal dan

\footnotetext{
${ }^{9}$ Anwar Kasir, Kitab Primbon Terjemah Abu Ma'syar Al-Falaki, (Surabaya: Maktab Said bin Nashir bin Nabhan, 1902), 10-13
} 
tabiat manusia di dunia. Untuk mengetahuinya maka terlebih dahulu dihitung namanya dan nama ibunya menggunakan hisab abajadun. Jumlahnya nanti dibagi 12. Sisanya kurang dari 12 atau genap 12, kemudian dihubungkan 12 bintang yang menunjukan hal ikhwal dan tabiat manusia seperti yang di bawah ini, setelah mengetahui gugusan bintangnya/ buruj/ zodiaknya, bintang, watak, kemudian perhatikan maksud bintang satu-persatu.

\begin{tabular}{|c|c|c|c|}
\hline Sisa & Buruj & Palintangan & Tabiat \\
\hline 1 & Khaml/ Aries & Mars & Api \\
\hline 2 & Tsur/ Taurus & Venus & Tanah \\
\hline 3 & Juza'/ Gemini & Merkurius & Hawa \\
\hline 4 & Sarthon/ Cancer & Rembulan & Air \\
\hline 5 & Asadun/ Leo & Matahari & Api \\
\hline 6 & Sanabilah/ Virgo & Merkurius & Tanah \\
\hline 7 & Mizan/ Libra & Venus & Hawa \\
\hline 8 & 'Aqrob/ Scorpio & Mars & Air \\
\hline 9 & Qus/ Sagitarius & Jupiter & Api \\
\hline 10 & Jatun/ Capricorn & Saturnus & Tanah \\
\hline 11 & Dalu/ Aquarius & Saturnus & Hawa \\
\hline 12 & Khawat/ Pisces & Jupiter & Air \\
\hline
\end{tabular}


Buruj dan palintangan untuk mengetahui hal ikhwal dan tabiat manusia itu dibagi menjadi dua macam: buruj laki-laki dan buruj wanita. Apabila yang ingin diketahui laki-laki maka menggunakan buruj laki-laki dan jika yang ingin diketahui perempuan maka menggunakan buruj perempuan. Peringkasannya memiliki mekanisme sendiri-sendiri.

Semisal contoh buruj laki-laki: Aries - Mars - Api

Aries: panas jika memiliki pangkat tinggi dianggap yang lain. Mars: bintangnya adalah kemuliaan, jalannya untung meski penuh rintangan (ibarat naik gunung dan tunun jurang), maka seorang bayi yang lahir bertepatan dengan Mars kulitnya coklat muda, tinggi orangnya, besar kepalanya, payah dalam tindakan, kadang suka emosi namun berangsur reda, welas asih, biasa bertualang, suka dengan perkara benar dan benci dengan sesuatu yang salah, apa yang diperbuat sesuai dengan apa yang dipikirkan, ajak-ajak rembukan agar tidak terjadi apa-apa, terkadang merasa fakir kadang merasa kaya, bertampang ganteng, sabar menghadapi keributan. ${ }^{10}$

Demikianlah sekilas isi kitab Abu Ma'syar Al-Falaki yang disebutkan di atas sebagai salah satu dari daftar kitab ilmu hisab --dan ternyata terdapat pembahasan tentang ramalan sebagaimana dalam primbon Jawa.

\section{Kesimpulan}

Penulis mengakui masih banyak kekurangan dari artikel ini baik dari segi kepenulisan maupun isi dari konten maklah itu sendiri, penulis menyadari biografi serta isi pemikiran yang disampaikan dalam makalah ini masih jauh dari kata sempurna disebabkan karena kurangnya sumber primer maupun sekunder yang membahas tentantang tokoh abu Mas'syar Alfalaky disisi lain kitab-kitab yang ada masih dalam bentuk bahasa arab yang penulis kurang memahami maksud dari isi pemikiran yang dituangkan dalam kitab tersebut. Oleh sebab itu penulis mencari sumber bacaan terjemahan namun dalam bentuk kitab ramalan jawa. Oleh sebab itu saya mengucapkan banyak terimaksih sekiranya dari pembaca mampu

\footnotetext{
${ }^{10}$ Ibid., 20-21
} 
melengkapi isi dari pembahasan maklah tersebut baik dari segi biografi intelektual serta pembahasan pemikiran tokoh falak Abu Mas'Syah Al-Falaky.

\section{Daftar Pustaka}

Anwar Kasir, Kitab Primbon Terjemah Abu Ma'syar Al-Falaki, (Surabaya:

Maktab Said bin Nashir bin Nabhan, 1902).

Azhari, Susiknan, "Penyatuan Kalender Islam Turki 2016", Seminar Nasional Kalender Islam Global Pasca Muktamar Turki 2016, (Medan: OIF UMSU, 2016).

, Catatan \& Koleksi Astronomi Islam \& Seni Jalan Menyingkap Keagungan Ilahi, (Yogyakarta: Museum Astronomi Islam, 2015).

2012)

Az-Zuhaili, Wahbah, At-Tafsīr al-Munīr: fì al-'Aqīdah wa asy-Syarī'ah wa alManhaj, Terj. Abdul Hayyie Al-Kattanih, dkk, "Tafsir al-Munir Jilid 5", (Depok: Gema Insani, t.th.).

Ensiklopedia Britannica, dictionary Merriam Webster online, diakses pada 29 September $2017 \mathrm{M}$.

Hudoyo ki hadayadiputro, Dasar-dasar Astrologi Hindu, (Surabaya: Penerbit Paramita, 2009)

Ismail, Imam Abi Abdillah Muhammad bin, Shahih Bukhari Juz 1, (Beirut: Daar al-Kutub al-'Alamiah, 1992).

Izzuddin, Ahmad, Fiqih Hisab Rukyah, (Jakarta: Erlangga, 2007). 2002).

Ivan Taniputra, Astrologi Dan sejarah Dunia, (Yogyakarta: Aplus Book, 2009).

Ophelia, Sukses Finansial lewat astrologi dan peta kehidupan, (Jakarta: Penerbit Buku Kompas, 2010) .

Kementerian Agama RI, Al-Qur'an dan Tafsirnya, (Jakarta: Kementerian Agama RI, 2012). 